\title{
A high-performance carbon-carbon(C/C) Quasi-Solid-State Supercapacitor with Conducting Gel Electrolyte
}

\author{
Dexuan Wang ${ }^{1, *}$, Liangmin $\mathrm{Yu}^{1, *}$, Benlin $\mathrm{He}^{2}$, Lei Wang $^{2}$ \\ ${ }^{1}$ Key Laboratory of Marine Chemistry Theory and Technology, Ministry of Education, Ocean \\ University of China, Qingdao 266100, PR China; \\ ${ }^{2}$ Institute of Materials Science and Engineering, Ocean University of China, Qingdao 266100, PR \\ China; \\ *E-mail: wangdexuan@stu.ouc.edu.cn, yuyan@ouc.edu.cn
}

doi: $10.20964 / 2018.03 .73$

Received: 13 December 2017 / Accepted: 17 January 2018 / Published: 5 February 2018

The development of the electric double-layer capacitors (EDLCs) that pursue for the advantages of easily carrying, no leaking and high capacitance has been a strong objective at the moment. Here a new type gel electrolyte with a high special conductivity of $15.06 \mathrm{mS} \cdot \mathrm{cm}^{-2}$ was fabricate by immersing polyacrylamide gel (PAM-G) matrix in $6 \mathrm{M} \mathrm{KOH}$ aqueous solution for 60 hours. As expected, the assembled quasi-solid-state supercapacitor based PAM-G electrolyte exhibits a specific capacitance (of $196 \mathrm{~F} \cdot \mathrm{g}^{-1}$ and $156 \mathrm{~F} \cdot \mathrm{g}^{-1}$ at the charge-discharge current density of $1 \mathrm{~A} \cdot \mathrm{g}^{-1}$ and $10 \mathrm{~A} \cdot \mathrm{g}^{-1}$, respectively), maximum power of $10 \mathrm{~kW} \cdot \mathrm{kg}^{-1}$ along with energy density of $28.6 \mathrm{Wh} \cdot \mathrm{kg}^{-1}$ (under the current density of $10 \mathrm{~A} \cdot \mathrm{g}^{-1}$ ), and the capacitance retention rate keeps $98 \%$ after 5000 cycles at $1 \mathrm{~A} \cdot \mathrm{g}^{-1}$, demonstrating a high cycling stability, an excellent rate capability as well as a high specific capacitance of the device. The promising electrochemical performance could be attributed to the unique homogeneous and microporous three-dimensional structure of the PAM-G which can greatly enhance the permeability and transportation of different ions.

Keywords: Quasi-solid-state supercapacitors; PAM-G matrix; Three-dimensional structure; Energy storage

\section{$\underline{\text { FULL TEXT }}$}

(C) 2018 The Authors. Published by ESG (www.electrochemsci.org). This article is an open access article distributed under the terms and conditions of the Creative Commons Attribution license (http://creativecommons.org/licenses/by/4.0/). 